\title{
Experimental Work on Cancer
}

$\mathrm{I}^{\mathrm{N}}$ the recently issued annual report of the Imperial Cancer Research Fund ${ }^{1}$, Dr. J. A. Murray records the main properties of twenty-eight different strains of animal tumours which are maintained in the laboratories of the Imperial Cancer Research Fund. He appeals to other institutes to publish similar "statements of the significant characteristics of the tumour strains maintained by them so that investigators throughout the world may more easily compare their material and results".

Rous and Murphy showed that fowl tumours transmissible by cell-free material retain their individual properties, in appearance, rate of growth and distribution of secondary tumours. In the first paper of the scientific report ${ }^{2}$, Dr. Foulds describes such characteristics for six different chicken tumours, and concludes that the behaviour of these tumours is parallel to that of metastases in human cancer. In a supplement to the report ${ }^{3}$, Dr. Foulds gives a detailed summary of the work on the properties of the filtrates which produce tumours in fowls and on the characteristics of such growths. The specificity of the malignant tissue produced by filterable agents and the multiplication of such agents with the growth of the tumour differentiates them from the chemical carcinogenic agents. On the other hand, the 'organisers' induce embryonic structures, the growth of which then appears to increase the amount of organiser.

The fourth and fifth papers of the report deal with investigations carried out by Dr. A. F. Watson on the effect of liver diet on tar cancer. Maisin showed that when either fresh or cooked liver was fed to mice, they became more susceptible to painting with carcinogenic tar. Watson has shown that a preparation of hog's stomach containing the hæmopoietic factor did not have the same effect as liver. The results of liver feeding show that the mortality of the control mice is much higher than that of the liver-fed animals; this effect seems to be greater than the influence on tumour production.

Dr. E. S. Horning has developed a technique by means of which the distribution of inorganic matter in tissues can be studied. The fixed and sectioned tissue is heated to $650^{\circ} \mathrm{C}$, after which the distribution of the ash can be seen by means of dark-ground illumination. From this, the form and character of the original cells can be seen. Hypertrophied stroma and most malignant cells appear to contain more inorganic matter than normal cells; in this respect, however, tar tumours seem to differ from other tumours. The method has shown that radium treatment causes redistribution of the inorganic matter ; changes are shown within six hours of irradiation and continue for six days. There seems no doubt that micro-incineration is a valuable histological and chemical method.

Mr. H. G. Crabtree and Dr. W. Cramer show that treatment of transplantable tumour tissue with the maximum concentration of poisons producing reversible inhibition of the respiration will also allow the tissue to grow when implanted in a host. If the poison is used in a higher concentration, the tissue will not grow on transplanting. They also show that the physiological environment affects the susceptibility to radium; in general, lowered respiration causes increased susceptibility. Dr. Cramer has been able to demonstrate that the differences in sensitivity to radium of spontaneous mammary carcinomata in mice are partly due to variations in the extent of macrophage invasion. He points out that effective radiation need not kill all the cells directly, but only cause temporary but specific damage.

The last two papers of the report are by Dr. R. J. Ludford and deal with the structure and behaviour of cells in tissue cultures of tumours. Macrophages, polyblasts, lymphocytes, giant cells, fibroblasts and malignant cells, all of which occur in such cultures, are described. Apart from their morphology, the cells can be differentiated by their movements and reactions to vital stains. Careful subculture has given almost pure cultures of malignant cells. Ludford has been able to use colloidal solutions of fat-soluble dyes as a vital stain for the fatty parts of cells. All cells are stained by such dyes, but as malignant cells are not stained by the water-soluble trypan blue, it is suggested that the plasma membrane of malignant cells is relatively rich in fatty substances. In this respect, the membrane resembles that of the tubercle bacillus.

Many of the papers are fully and beautifully illustrated, and the descriptions immediately below the plates themselves are a great help to the reader.

\footnotetext{
${ }^{1}$ Thirty-second Annual Report (1933-1934) of the Imperial Cancer Research Fund.

${ }^{2}$ Eleventh Scientific Report on the Investigations of the Imperial Cancer Research Fund. Pp. ix $+177+58$ plates. (London: Taylor and Francis, 1934.) 308.

${ }^{3}$ Supplement to the Eleventh Scientific Report on the Investigations of the Imperial Cancer Research Fund. The Filterable Tumours of Fowls: a Critical Review. Pp. ii +42 , (London: Taylor and Francis, 1934.) n.p.
}

\section{Annual Meeting of the Science Masters Association}

THE thirty-fifth annual meeting of the Science Masters Association was held on January 1-4 at Oxford under the presidency of Prof. N. V. Sidgwick. Some three hundred members were present, a number slightly less than the usual number for an Oxford meeting, although the membership of the Association has risen to within the region of two thousand.

A full programme of lectures, visits and demonstrations was arranged, together with the usual exhibits by manufacturers and publishers. Various departments of the University were open for inspection and special demonstrations were staged, par- ticularly in the Astronomical, Biochemical, Botanical, Electrical and Chemical Departments.

The presidential address, under the title of "Real Molecules", was a lucid account of the modern physical conceptions of atoms and molecules developed as the result of the applications of the ideas of wave mechanics, which, in the opinion of Prof. Sidgwick, affect only to a slight degree the dimensions of atoms and their orbits as deduced from the classical theory, but give a much clearer conception of the mechanism of covalency. By assigning to every nucleus a sphere of influence, the dimensions 
of which can be ascertained by X-ray methods and spectroscopy, and by defining the size of an atom as that portion of space into which other atoms cannot enter, it is possible to avoid the difficulty created by wave mechanics of a cloud of electrons of indefinite size surrounding the nucleus. Using this conception of the size of atoms, combined with a knowledge of the angles between the valencies, a molecular model can be built up. This model, however, has a volume much less than the molecular volume obtained in other ways. Hence it becomes necessary to assume the existence of an envelope (due to the electrostatic repulsion of the electrons of different atoms within the molecule) surrounding an atom in combination, the thickness of the envelope being dependent on the various types of linkage. The effects of molecular collisions on molecular change were also discussed, with particular reference to the possibilities of twisting component parts of the molecules round the valency bonds, the compression and rarefaction of the bonds, and the alteration of their angular values.

Mr. C. N. Hinshelwood gave a lecture on "Some Aspects of Modern Physical Chemistry", discussing the significance to chemistry of quantum mechanics, which, he said, has added new laws and methods of calculation in physical chemistry without disturbing existing laws to any great extent. Zero point energy, chain reactions, structure of liquids, and heavy hydrogen were topics included in this survey

An evening lecture was given by Prof. H. H. Plaskett on the "Physics of Astronomical Vacua", with special reference to the density and source of luminosity of gaseous nebulæ. The lecture was followed by an inspection of the University Observatory. "The New Aspect of the Elementary Theory of Organic Chemistry" was taken by Prof. R. Robinson as the subject of another evening lecture, in which, using the conception of anionoid and cationoid reagents, he showed how the electron theory is resulting in a unification of physics and organic chemistry. Other lectures were "Plant Respiration" by Dr. W. O. James, "Ionisation by Collision" by Prof. J. S. E. Townsend, "Tissue Respiration" by Mr. R. B. Fisher. All these lectures were much appreciated by members of the Associa- tion, for whom much of the value of these annual meetings lies in the lucid résumés of modern work by experts in their various subjects.

A lecture-demonstration which attracted much attention was given by Dr. K. J. Franklin on "X-ray Cinematography". This was illustrated by films of the circulation of the blood and respiratory movements of various mammals.

Sound film demonstrations formed a large and interesting part of the general programme of the annual meeting. Three films were shown, suggested as suitable films for class science teaching by the British Film Institute, on which body the Science Masters Association has representatives. The films were "The Molecular Theory of Matter", "Sound and its Production", and "The Cathode Ray Oscillograph". While all these films did not find favour in every particular (indeed humour was provoked in unexpected places), it was realised that here is a valuable addition to teaching technique, particularly as a method of revision. Difficulties in the matter of cost, standard projectors, silent versus talking films, were raised and discussed at the demonstrations.

At the business meeting, the following elections took place : President, Sir William Bragg; Secretary, S. V. Brown (Liverpool Institute); Annual Meeting Secretary, R. E. Williams (Repton); New Committee Members, Dr. W. G. Davis (Newcastle Grammar School), L. G. Smith (Marylebone Grammar School), F. R. Snell (Eastbourne College). Changes were made in the rules to permit of the election of honorary members, and all past presidents were elected to that dignity. The annual report showed that the Association has now 1921 members representing 797 schools, an increase in the year of 109 members and 40 schools. The branch organisation of the Associa. tion is proceeding apace. The North Eastern, South Wales and North Western branches have been in existence for several years. Other branches in Yorkshire, East Anglia and possibly Middlesex are in process of formation. This branch organisation, it is realised, is likely to involve difficulties of representation.

The annual meeting for 1936 will be held in London under the presidency of Sir William Bragg.

\section{Periodic Variations in the Mean Focal Depth of Japanese Earthquakes}

\section{By Dr. Charles Davison}

D URING the last ten years, many estimates have been made of the focal depths of earthquakes in Japan. They depend on the duration of the preliminary tremors at three or more neighbouring stations. Two lists have been published, one by Mr. $\mathrm{N}$. Nasu of the after-shocks of the Tango earthquake of March 7, 1927 (Earthq. Res. Inst. Bull., 6, 245-331 ; $7,133-152 ; 1929)$, the other of ordinary earthquakes felt in Tokyo from 1924 onwards, now issued quarterly by the Earthquake Research Institute.

After-Shocks of the Tango Earthquake of 1927.Mr. Nasu has determined the position of the epicentre and the depth of the focus of 482 shocks from March 11,1927 , to July 16,1928 . The values obtained for the depths range from 0 to $44 \mathrm{~km}$., the mean of all being $15.4 \mathrm{~km}$. or, excluding zero estimates, $15.9 \mathrm{~km}$. The after-shocks are subject to several well-marked periods-of one day, $29 \cdot 6,14 \cdot 8$ and $7 \cdot 4$ days, and 42 minutes.
From March 14 to August 31, the focal depths of 438 after-shocks are given. The maximum epoch of the diurnal period in the frequency of these shocks occurs at 3 a.m., the amplitude of the period being $0 \cdot 24$. During the same interval, the mean depth of the foci was $14.9 \mathrm{~km}$., and the mean depth during successive hours is also subject to a diurnal period with its maximum at $3 \mathrm{a.m}$. and its amplitude $0 \cdot 03$, that is, the oscillations in mean depth due to this period range within about $0.45 \mathrm{~km}$. of the mean.

The lunar periods are more clearly marked. During the 16 lunations from April 2, 1927, to July 17, 1928, the depths of 247 foci were estimated, the mean of all being $16.7 \mathrm{~km}$. For both frequency and mean depth, the maximum epoch of the $29 \cdot 6$ day period falls not far from the time of full moon, the ampli. tudes being 0.37 and 0.09 ; the epochs of the 14.8 day period fall close to the times of first and last quarters, with amplitudes of 0.39 and 0.09 , and those 